\title{
PERCURSOS MIGRATÓRIOS NO ESTADO DE SÃO PAULO uma análise do período $1995-2000$
}

Sonia Regina Perillo

Magaly de Losso Perdigão

\begin{abstract}
Resumo: Este estudo tem como objetivo acompanhar a trajetória da migração no Estado de São Paulo na década de 90. Para tal, são utilizadas as informações provenientes do Censo Demográfico 2000, que possibilitam a identificação dos fluxos migratórios interestaduais e intra-estaduais ocorridos em São Paulo nesse período. Palavras-chave: Redistribuição espacial. Fluxos migratórios. Áreas de origem e destino.

Abstract: The objective of this study is to follow the trajectory of migration in the State of São Paulo in the decade of 90. For such purpose are used the information proceeding from the Demographic Census 2000, that make possible the identification of the migratory flows occurrences inside the State of São Paulo and between São Paulo and other States of Brazil in this period.

Key words: Space redistribution. Migratory flows. Areas of origin and destination.
\end{abstract}

A s últimas décadas foram marcadas por transformações socioeconômicas e políticas profundas, tanto em âmbito mundial como nacional. Essas mudanças tiveram desdobramentos importantes, alterando os padrões da redistribuição espacial da população. Tendo em vista que grande parte da economia industrial do país concentra-se na Região Sudeste, sobretudo no Estado de São Paulo, os efeitos desse processo incidiram fortemente no território paulista.

Este artigo propõe-se a colaborar nessa direção, acompanhando os deslocamentos populacionais ocorridos no Estado de São Paulo e apontando as principais alterações na dinâmica migratória paulista nos anos recentes.

\section{CONSIDERAÇÕES METODOLÓGICAS}

As dificuldades inerentes à análise dos deslocamentos populacionais têm origem na própria definição do fenô- meno. A migração comporta várias interpretações, que apresentam como única idéia comum a dimensão temporal e espacial. Acresça-se a dificuldade de mensuração e/ou interpretação dessa variável, bem como uma série de restrições quanto à disponibilidade dos dados e metodologias de análise. Além disso, a falta de registros contínuos dos deslocamentos populacionais faz com que a análise da migração fique praticamente dependente das informações disponíveis nos censos demográficos.

Há que se lembrar que a adoção de uma definição de "migrante" também apresenta algumas dificuldades adicionais relacionadas à natureza espacial da unidade de análise adotada que, por sua vez, depende do tipo de fluxo migratório a ser analisado (interestadual, intra-estadual, intermunicipal, entre outros).

Tomando-se como base as considerações estabelecidas acima, este estudo utilizará as informações sobre migração provenientes do Censo Demográfico 2000, que per- 
mitem definir como "migrantes" as pessoas com 5 anos ou mais de idade cuja Unidade da Federação - UF de residência em uma data fixa era distinta daquela em que residiam no momento da pesquisa. Em 1991, essa data fixa correspondia a 01/09/1986; e, em 2000, a 31/07/1995.

No contexto dos deslocamentos interestaduais serão considerados "imigrantes" todas as pessoas com 5 anos ou mais de idade, que residiam fora do Estado de São Paulo em 31/07/1995. As unidades de análise serão as Grandes Regiões e as UFs.

Como "emigrantes" serão consideradas as pessoas com 5 anos ou mais de idade cuja UF de residência em 31/07/1995 era São Paulo e que, no momento do Censo, residiam em outra UF brasileira, exceto São Paulo.

No caso dos fluxos intra-estaduais, será analisado o Estado de São Paulo - considerando-se como recorte analítico a Região Metropolitana de São Paulo - RMSP e o interior do Estado. ${ }^{1}$ Serão avaliados os deslocamentos populacionais ocorridos entre as 15 Regiões Administrativas - RAs que integram o Estado e, serão considerados migrantes interestaduais as pessoas com 5 anos ou mais de idade cujo município de residência anterior (em 31/07/1995) não pertença à RA onde foram recenseados.

Assim, será dada ênfase aos fluxos migratórios numericamente mais importantes segundo os volumes de imigração e emigração registrados no período 1995-2000. Essas informações permitirão detectar as trocas líquidas de população (diferença absoluta entre o volume de imigrantes e emigrantes) e os respectivos ganhos ou perdas populacionais de cada área envolvida nos fluxos.

É importante destacar que as informações analisadas possibilitarão identificar e quantificar apenas os "migrantes recentes", ou seja, os que migraram entre 1995 e 2000. Ressalte-se a impossibilidade de se resgatar o processo migratório por que passaram os indivíduos durante todo o período censitário (1991-2000), pois a pergunta elaborada pelo Censo só permite auferir os deslocamentos ocorridos entre 1995 e 2000.

\section{MIGRAÇÃO NO CONTEXTO DAS TRANSFORMAÇÕES ECONÔMICO-SOCIAIS NO PERÍODO 1980-2000}

Segundo alguns especialistas da área econômica, até os anos 70, a dinâmica e a localização das atividades industriais pautavam, em grande medida, os possíveis caminhos da população no Estado de São Paulo. Nesse contexto, a RMSP consolidava-se como o grande centro econômico-financeiro nacional e desempenhava o papel de maior área de concentração populacional do país. De fato, o volume de migração para a metrópole chegou a superar dois milhões de pessoas na década de 70, mostrando-se como a variável determinante do seu crescimento - respondendo por $51,6 \%$ do incremento demográfico entre 1970 e 1980 (PERILLO, 1993; RODRIGUES; PERILLO, 1986).

Na década de 80 , o poder de atração exercido pela indústria paulista diminuiu consideravelmente, repercutindo de forma pronunciada no mercado de trabalho e nos movimentos populacionais. A profunda recessão que abalou o país nos anos 80 atingiu predominantemente a atividade industrial, provocando queda generalizada nos níveis de atividades, de emprego e de renda. Tendo em vista que grande parte da economia industrial do país concentra-se na Região Sudeste, sobretudo no Estado de São Paulo, os efeitos dessa crise econômica incidiram fortemente no território paulista.

Tanto na metrópole como no interior do Estado, a recessão dos anos 80 veio somar-se aos efeitos do processo de "desconcentração metropolitana decorrente dos custos de aglomeração" e da "interiorização do desenvolvimento econômico", fazendo com que a RMSP apresentasse um arrefecimento importante em seu dinamismo econômico e populacional.

Nos anos 90, novos fatores passaram a interferir na dinâmica econômica e migratória estadual. Com a abertura comercial e financeira e a conseqüente internacionalização da economia, a política econômica vigente induziu a processos de reestruturação da base produtiva. Os principais setores que compunham o parque industrial buscaram novos mercados e incrementaram a produtividade por meio de estratégias de competitividade. Esse movimento provocou não apenas a "liberalização econômica", como também foi responsável pela quebra de empresas, transferências patrimoniais, mudanças nos padrões tecnológicos, alteração dos métodos e modelos de gestão e eliminação de empregos, entre outros.

Do ponto de vista da oferta de emprego, que é um fator fundamental para a compreensão dos movimentos migratórios, os levantamentos mensais da Pesquisa de Emprego e Desemprego - PED, realizada pela Fundação Seade e pelo Dieese desde 1985, apuraram os impactos dessas mudanças no mercado de trabalho na RMSP. No período 1985-2002, o nível de emprego recuou e as taxas de desemprego total expandiram-se, atingindo 19,0\% em 2002. 
Segundo Branco (1999)

à medida que avançava o desemprego na Região Metropolitana, cresciam as tentativas analítico-explicativas de associá-lo aos processos de reestruturação produtiva e de recolocação da atividade industrial.

De fato, a reestruturação na atividade produtiva, sobretudo no setor industrial, eliminou significativa parcela de postos de trabalho, ao mesmo tempo em que a terceirização de atividades, antes realizadas na planta industrial, contribuiu para que parte dos empregos eliminados fossem incrementados nos serviços. Em termos setoriais, a PED mostrou que, enquanto a proporção de ocupados na indústria da RMSP diminuiu de $32,6 \%$ para $20 \%$ no período entre 1995 e 2002, a participação dos ocupados nos serviços passou de $40 \%$ para $52,6 \%$ no mesmo período. O comércio, por sua vez, registrou um pequeno aumento na proporção de ocupados, de $14 \%$ para $16 \%$ entre 1995 e 2002.

Diante desse contexto, pode-se dizer que, se até os anos 70, a localização e a ampliação das atividades urbano-industriais direcionavam os caminhos da migração em São Paulo, nas décadas de 80 e sobretudo 90, a capacidade de atração migratória pela indústria transformou-se sensivelmente. Esta parece ser agora exercida pela interação dos investimentos na produção industrial e na capacidade que esses investimentos têm na demanda por mais serviços e mão-de-obra.

As mudanças na estrutura industrial não significaram uma diminuição de sua importância na estrutura produtiva do Estado, mas sim uma modernização - e, portanto, um fortalecimento dessa atividade. Para se ter uma idéia da importância da indústria, em 1996, São Paulo concentrava quase $50 \%$ das atividades industriais do país, $53 \%$ da produção da indústria mecânica, $60 \%$ da química, $62 \%$ de material de transportes, $70 \%$ de borracha, $65 \%$ de produtos de materiais plásticos - para citar apenas alguns gêneros da indústria de transformação.

Em 1996, mesmo com todas as mudanças ocorridas, a metrópole apresentou elevada participação na produção industrial do Estado com 60,4\% do valor adicionado, $56,8 \%$ do pessoal ocupado e $57 \%$ das unidades locais. As regiões do interior, beneficiadas pela "interiorização do desenvolvimento", exibiram um elevado grau de complementaridade e de integração técnica e funcional com a RMSP. Esse processo é muito mais significativo nas regiões situadas no entorno metropolitano que abrange Campinas, RM da Baixada Santista, São José dos Campos e
Sorocaba. A evidência mais completa dessa integração está no fato de que a matriz produtiva de São Paulo, em seus principais gêneros, completa-se nesse entorno. Em 1996, mais de $90 \%$ do valor adicionado estadual estava aí concentrado: 96\%, na fabricação de produtos químicos; 99\%, na fabricação e montagem de veículos automotores, reboque e carrocerias; e $91 \%$, na fabricação de máquinas e equipamentos. A exceção é a indústria de alimentos e bebidas, mais espraiada pelo interior do Estado (ARAÚJO, 1999).

Nos anos 90, dando continuidade à década anterior, mesmo em menores proporções, verifica-se um processo de interiorização econômica e populacional do Estado. Segundo Araújo (1999), esse processo ocorreu em um espaço concentrado num raio de aproximadamente $150 \mathrm{~km}$ a partir do centro da metrópole, abrangendo as regiões de Campinas, São José dos Campos, RM da Baixada Santista e Sorocaba. A autora mostra que diversos fatores contribuíram de forma decisiva para a continuidade da desconcentração metropolitana e fortalecimento do interior, dentre eles: as condições estruturais existentes no interior, os investimentos maciços em infra-estrutura energética, de transportes e comunicações, o crescimento da agroindústria da cana e da laranja, a proximidade do mercado consumidor, dentre outros.

As mudanças apontadas no cenário econômico tiveram desdobramentos importantes, alterando os padrões de redistribuição espacial da população (PERILLO, 2002; OLIVEIRA; SIMÕES, 2004; BAENINGER, 2002; 2004).

Diversos estudos já destacaram que o relevante papel da migração em São Paulo contribuiu para a manutenção das elevadas taxas de crescimento da população, até os anos 70. As décadas seguintes foram marcadas por uma desaceleração dos movimentos migratórios e do ritmo de crescimento demográfico. Mesmo assim, entre 1991 e 2000, a população paulista cresceu a uma taxa anual de $1,8 \%$ - superior à média nacional, de 1,6\%. Dentro de um contexto demográfico em que o crescimento vegetativo (nascimentos menos óbitos) tende a ser cada vez mais homogêneo, o componente migratório continua tendo papel decisivo para o entendimento da dinâmica demográfica do Estado de São Paulo. De fato, a redução nas taxas de crescimento da população paulista nas últimas décadas reflete, em grande medida, as mudanças ocorridas em seus movimentos migratórios.

As informações sobre migração disponíveis no Censo Demográfico 2000 permitem o acompanhamento das tendências migratórias recentes em São Paulo. Segundo es- 
sas informações, verifica-se que algumas modalidades de deslocamentos populacionais confirmaram-se e fortaleceram-se na década de 90 - como os movimentos intra-estaduais no território paulista. A mobilidade interestadual continuou tendo importância; porém, desde a década de 80 , vem perdendo peso relativo na composição da migração. Em contrapartida, a migração intra-estadual ganhou destaque, aumentando sua participação no cenário migratório nos anos recentes.

\section{O CONTEXTO DOS MOVIMENTOS MIGRATÓRIOS INTERESTADUAIS}

A liderança econômica do Estado de São Paulo no cenário brasileiro sempre lhe garantiu elevada concentração populacional e uma trajetória marcada por intensos movimentos migratórios. Com efeito, São Paulo vem protagonizando, há várias décadas, o processo de redistribuição da população no território brasileiro, destacando-se como a principal área de concentração populacional do país. Em 2000, contava com 37 milhões de habitantes e respondia por $21,8 \%$ da população nacional. Os movimentos migratórios interestaduais sempre desempenharam papel relevante na composição da população paulista. Em 2000, praticamente $75,2 \%$ de sua população correspondia a pessoas nascidas no próprio Estado (naturais) e $24,8 \%$ a pessoas nascidas em outros Estados brasileiros e outros países (não-naturais). Vale dizer: em 2000, residiam em São Paulo aproximadamente 9,1 milhões de pessoas não-naturais do Estado, com predominância dos mineiros $(20,7 \%)$, baianos $(19,7 \%)$, paranaenses $(12,9 \%)$ e pernambucanos $(12,4 \%)$.

São Paulo, segundo o Censo 2000, continuou se consolidando como a UF que registrou o maior volume de migrantes do país - o que determinou intensa mobilidade populacional em seu território. No período 1986-1991, recebeu 1,4 milhão de migrantes interestaduais e em 1995-2000, 1,2 milhão de pessoas - o que indica uma redução de $12 \%$ nos deslocamentos interestaduais. Por outro lado, entre 1986 e 1991, 648 mil pessoas saíram de São Paulo em direção a outros estados brasileiros (emigrantes) e, entre 1995 e 2000, 884 mil pessoas - o que representou um aumento de $36 \%$. O Estado de São Paulo prevaleceu como porta de entrada da população nacional; porém, o volume dos deslocamentos interestaduais para o Estado vêm diminuindo progressivamente ao longo das décadas. Paralelamente a esse fenômeno, entre 1995 e 2000, São Paulo apresentou um aumento da emigração de sua população para os outros estados brasileiros. Os principais fluxos migratórios ocorridos entre o Estado de São Paulo e as Grandes Regiões do país, no período 1995-2000, podem ser observados no Mapa 1.

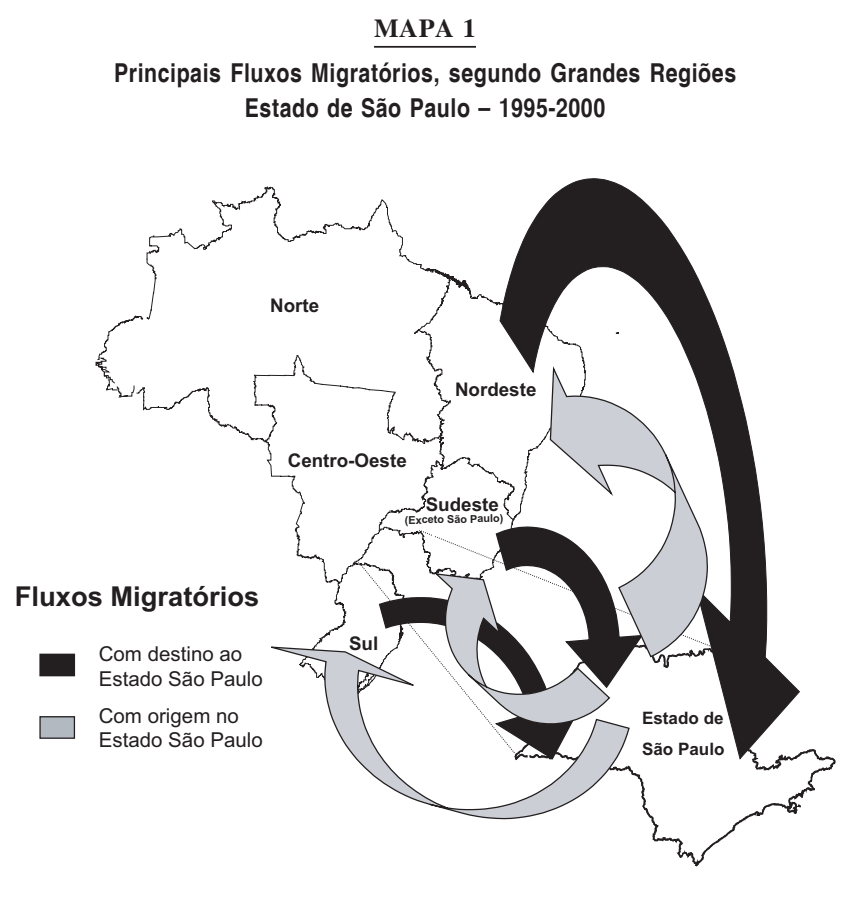

Fonte: IBGE; Fundação Seade.

\section{Origem dos Migrantes que Chegaram ao Estado de São Paulo}

A diminuição do volume de migrantes interestaduais que chegaram ao Estado de São Paulo entre 1995-2000 não está vinculada à redução dos fluxos procedentes do Nordeste. De fato, nos períodos entre 1986-1991 e 1995-2000, São Paulo permaneceu como o principal destino desses fluxos, e a migração de nordestinos mantevese em níveis semelhantes, aproximadamente 720 mil pessoas (Tabela 1). Verificou-se, inclusive, um aumento da participação relativa dos nordestinos no total dos migrantes do Estado - de 51,7\%, entre 1986-1991, para 57,7\%, entre 1995-2000 - e uma acentuada redução da participação dos fluxos do Sudeste e do Sul, no mesmo período (Gráfico 1). Ainda assim, os deslocamentos com origem na Região Sudeste representaram 19\% da imigração para o Estado de São Paulo, entre 1995-2000. Segue-se a Região Sul, responsável por $13,5 \%$ dos migrantes que chegaram ao Estado. Sobressaíram-se os fluxos procedentes 
TABELA 1

Volume de Imigração e Emigração Interestaduais, segundo Grandes Regiões Brasileiras Estado de São Paulo - 1986-2000

\begin{tabular}{lrrrrr}
\hline \multirow{2}{*}{ Regiões } & \multicolumn{2}{c}{ Imigração } & & \multicolumn{2}{c}{ Emigração } \\
\cline { 2 - 3 } \cline { 5 - 6 } Brasil & $1986-1991$ & $1995-2000$ & & $1986-1991$ & $1995-2000$ \\
Norte & 34.797 & 31.194 & & 21.426 & 29.137 \\
Nordeste & 720.565 & 716.697 & & 211.412 & 325.529 \\
Sudeste (1) & 308.242 & 239.906 & & 189.309 & 258.836 \\
Sul & 245.270 & 168.180 & & 130.779 & 173.983 \\
Centro-Oeste & 83.922 & 86.998 & & 95.065 & 96.539 \\
\hline
\end{tabular}

Fonte: IBGE; Fundação Seade.

(1) Considerou-se a Região Sudeste, exceto o Estado de São Paulo.

dos Estados da Bahia (22,7\%), Minas Gerais (14,6\%), Pernambuco e Paraná (10,7\%) (Tabelas 2 e 3). O Estado de São Paulo permaneceu como importante porta de entrada da população que se deslocou da Região Nordeste. Por outro lado, diminuiu a potencialidade migratória do Estado com relação às Regiões Sul e Sudeste. As Regiões Norte e Centro-Oeste não mostraram mudanças pronunciadas nas trocas migratórias estabelecidas com o Estado, no período 1995-2000 (Gráfico 1).

\section{GRÁFICO 1}

Migrantes Interestaduais, segundo Local de Origem Estado de São Paulo - 1986-2000

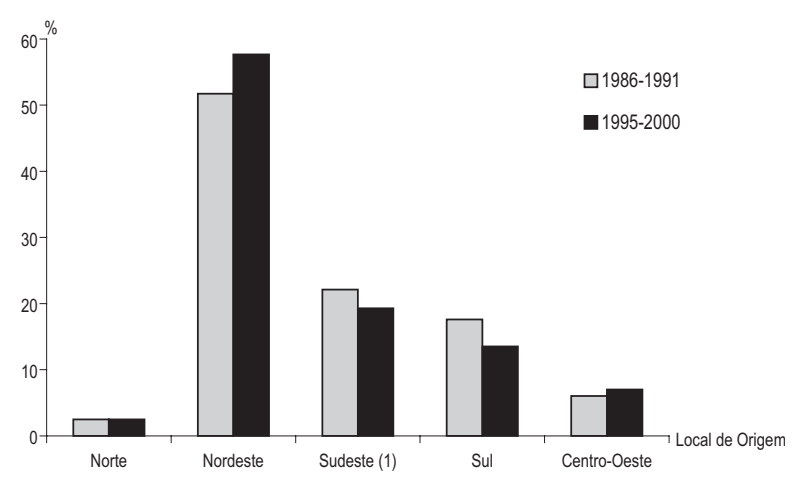

Fonte: IBGE; Fundação Seade.

(1) Considerou-se a Região Sudeste, exceto o Estado de São Paulo.
A RMSP destacou-se como a área mais atrativa dos migrantes interestaduais. São Paulo não conseguiu atrair população interestadual na mesma intensidade que nas décadas passadas; porém, a RMSP continuou desempenhando papel relevante no direcionamento dos fluxos provenientes de outros Estados brasileiros. Essa área re-

TABELA 2

Volume de Imigração e Emigração Interestaduais, segundo Regiões e Unidades da Federação Brasileiras Estado de São Paulo - 1986-2000

\begin{tabular}{|c|c|c|c|c|}
\hline \multirow{2}{*}{$\begin{array}{l}\text { Regiões e } \\
\text { Unidades da } \\
\text { Federação }\end{array}$} & \multicolumn{2}{|c|}{ Imigração } & \multicolumn{2}{|c|}{ Emigração } \\
\hline & 1986-1991 & $1995-2000$ & 1986-1991 & $1995-2000$ \\
\hline BRASIL & 1.392 .796 & 1.242 .974 & 647.991 & 884.024 \\
\hline Região Norte & 34.797 & 31.194 & 21.426 & 29.137 \\
\hline Acre & 810 & 787 & 780 & 626 \\
\hline Amapá & 225 & 504 & 322 & 631 \\
\hline Amazonas & 3.742 & 3.523 & 2.622 & 4.176 \\
\hline Pará & 14.656 & 14.129 & 5.655 & 9.002 \\
\hline Rondônia & 12.735 & 7.349 & 8.179 & 8.701 \\
\hline Roraima & 418 & 570 & 578 & 670 \\
\hline Tocantins & 2.211 & 4.332 & 3.290 & 5.330 \\
\hline \multicolumn{5}{|l|}{ Região } \\
\hline Nordeste & 720.565 & 716.697 & 211.412 & 325.529 \\
\hline Alagoas & 52.326 & 63.590 & 13.361 & 19.105 \\
\hline Bahia & 248.600 & 281.648 & 58.544 & 105.830 \\
\hline Ceará & 94.929 & 67.424 & 28.585 & 52.502 \\
\hline Maranhão & 18.029 & 33.061 & 5.760 & 9.865 \\
\hline Paraíba & 58.743 & 49.541 & 18.650 & 28.349 \\
\hline Pernambuco & 164.909 & 133.547 & 52.321 & 58.364 \\
\hline Piauí & 43.523 & 46.290 & 10.819 & 23.367 \\
\hline \multicolumn{5}{|l|}{ Rio Grande } \\
\hline do Norte & 23.657 & 19.755 & 13.182 & 17.855 \\
\hline Sergipe & 15.849 & 21.841 & 10.190 & 10.293 \\
\hline \multicolumn{5}{|l|}{ Região } \\
\hline Sudeste & 308.242 & 239.906 & 189.309 & 258.836 \\
\hline Espírito Santo & 8.865 & 10.995 & 10.827 & 11.850 \\
\hline Minas Gerais & 236.086 & 181.216 & 145.823 & 201.880 \\
\hline Rio de Janeiro & 63.291 & 47.694 & 32.659 & 45.105 \\
\hline Região Sul & 245.270 & 168.180 & 130.779 & 173.983 \\
\hline Paraná & 217.406 & 133.350 & 97.962 & 131.094 \\
\hline \multicolumn{5}{|l|}{ Rio Grande } \\
\hline do Sul & 16.222 & 18.443 & 13.397 & $\begin{array}{l}14.546 \\
28.343\end{array}$ \\
\hline Santa Catarina & 11.642 & 16.387 & 19.420 & 28.343 \\
\hline \multicolumn{5}{|l|}{ Região } \\
\hline Centro-Oeste & 83.922 & 86.998 & 95.065 & 96.539 \\
\hline Distrito Federal & 9.546 & 9.981 & 7.673 & 12.520 \\
\hline Goiás & 17.330 & 19.870 & 20.497 & 27.976 \\
\hline Mato Grosso & 21.192 & 21.790 & 25.006 & 19.793 \\
\hline $\begin{array}{l}\text { Mato Grosso } \\
\text { do Sul }\end{array}$ & 35.854 & 35.358 & 41.889 & 36.250 \\
\hline
\end{tabular}

Fonte: IBGE. Censos Demográficos 1991 e 2000. 
TABELA 3

Imigração, segundo Regiões Administrativas

Estado de São Paulo - 1995-2000

\begin{tabular}{lrcc}
\hline \multirow{2}{*}{ Regiões Administrativas } & \multicolumn{3}{c}{ Imigração (Origem) } \\
\cline { 2 - 4 } & \multicolumn{1}{c}{ Total } & Em São Paulo & $\begin{array}{c}\text { Fora de } \\
\text { São Paulo }\end{array}$ \\
\hline Estado de São Paulo & $\mathbf{2 . 2 6 8 . 9 5 1}$ & 45,2 & 54,8 \\
RMSP & 889.626 & 19,3 & 80,7 \\
Registro & 20.415 & 75,5 & 24,5 \\
RM da Baixada Santista & 141.558 & 58,3 & 41,7 \\
São José dos Campos & 131.646 & 50,0 & 50,0 \\
Sorocaba & 168.537 & 68,8 & 31,2 \\
Campinas & 410.578 & 57,1 & 42,9 \\
Ribeirão Preto & 67.892 & 52,9 & 47,1 \\
Bauru & 64.983 & 76,7 & 23,3 \\
São José do Rio Preto & 94.911 & 71,1 & 28,9 \\
Araçatuba & 46.491 & 71,7 & 28,3 \\
Presidente Prudente & 53.687 & 66,4 & 33,6 \\
Marília & 60.092 & 74,5 & 25,5 \\
Central & 61.037 & 64,5 & 35,5 \\
Barretos & 23.897 & 69,9 & 30,1 \\
Franca & 33.601 & 49,2 & 50,8 \\
\hline
\end{tabular}

Fonte: IBGE; Fundação Seade.

(1) Refere-se à soma dos fluxos migratórios intraestaduais e interestaduais ocorridos no/para o Estado de São Paulo entre 1995 e 2000.

cebeu 720 mil migrantes de outros Estados - o que representava $58 \%$ da imigração paulista no período. Destacaram-se os fluxos procedentes da Região Nordeste, sobretudo dos Estados da Bahia $(29,1 \%)$ e Pernambuco $(14,1 \%)$ (Tabelas 2 e 3). A importância dos deslocamentos interestaduais para a RMSP também pode ser contemplada quando se verifica que $81 \%$ dos deslocamentos para esta área tiveram origem em outros Estados brasileiros, contra apenas $19 \%$ ocorridos no próprio Estado de São Paulo (Tabela 3).

O Município de São Paulo manteve seu papel de grande área de atração da população de outros Estados para a RMSP. Para a capital paulista, deslocaram-se $410 \mathrm{mil}$ migrantes interestaduais, principalmente, dos Estados da Bahia (30\%), Pernambuco (13,1\%) e Minas Gerais (9,6\%).

$\mathrm{O}$ interior do Estado recebeu 525 mil migrantes de outros Estados brasileiros, procedentes, em sua maioria, das Regiões Nordeste (37,2\%), Sudeste $(25,7 \%)$ e Sul $(22,2 \%)$ (Gráfico 2). Sobressaíram-se os deslocamentos com origem nos Estados de Minas Gerais (20,5\%), Paraná $(19,1 \%)$ e Bahia (13,9\%). No contexto regional, a migração interestadual representou quase $50 \%$ do total dos fluxos, em regiões

\section{GRÁFICO 2}

Migrantes Interestaduais, segundo Local de Origem Região Metropolitana de São Paulo e Interior - 1995-2000
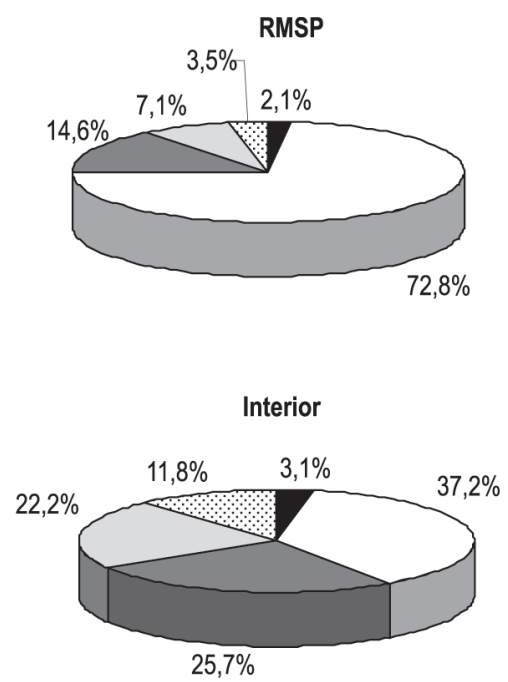

— Norte $\square$ Nordeste $\square$ Sudeste (1) $\square$ Sul $@$ Centro-Oeste

Fonte: IBGE. Censo Demográfico 2000.

(1) Refere-se ao Estado de São Paulo, excluindo-se a RMSP.

como Franca, São José dos Campos e Ribeirão Preto. Em outras áreas, como as regiões de Bauru, Registro, Marília, São José do Rio Preto e Araçatuba, a participação dos deslocamentos interestaduais foi menos expressiva.

\section{Destino dos Migrantes que Saíram do Estado de São Paulo}

Entre 1986 e 1991, 648 mil pessoas deixaram o Estado de São Paulo em direção a outros estados brasileiros; entre 1995 e 2000, esse volume passou a 884 mil pessoas - o que representou um aumento de $36 \%$ na emigração paulista (Tabela 1). Os principais locais de destino dos migrantes que saíram de São Paulo foram as Regiões Nordeste $(36,8 \%)$, Sudeste $(29,3 \%)$ e Sul $(19,7 \%)$ (Gráfico 3). Um aspecto importante a se ressaltar é que, entre os migrantes que saíram do Estado e foram para a Região Nordeste (325 mil pessoas), 62\% (200 mil pessoas) eram migrantes nordestinos na condição de retorno aos seus estados de nascimento e 26,5\% (86 mil pessoas) eram migrantes nascidos no Estado de São Paulo. Destacaramse como importantes locais de destino dos emigrantes de São Paulo, Minas Gerais (22,8\%), Paraná (14,8\%), Bahia $(12,0 \%)$ e Pernambuco $(6,6 \%)$. 


\section{GRÁFICO 3}

Migrantes Interestaduais, segundo Local de Destino Estado de São Paulo - 1986-2000

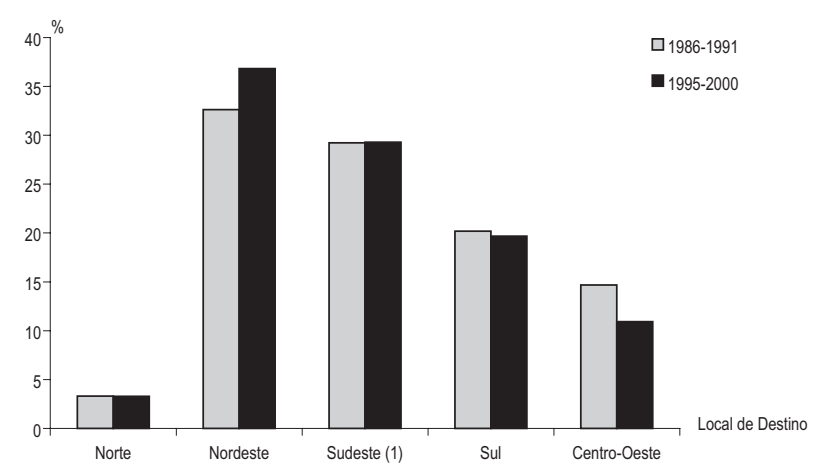

Fonte: IBGE; Fundação Seade.

(1) Considerou-se a Região Sudeste, exceto o Estado de São Paulo.

Mesmo considerada o grande pólo de atração populacional do Estado, a RMSP caracterizou-se como a principal área de saída da população no período 1995-2000. Tal tendência vinha sendo apontada desde a década de 70, e persistiu até 2000: 544 mil pessoas saíram de lá em direção

\section{GRÁFICO 4}

Migrantes Interestaduais, segundo Local de Destino Região Metropolitana de São Paulo e Interior - 1995-2000
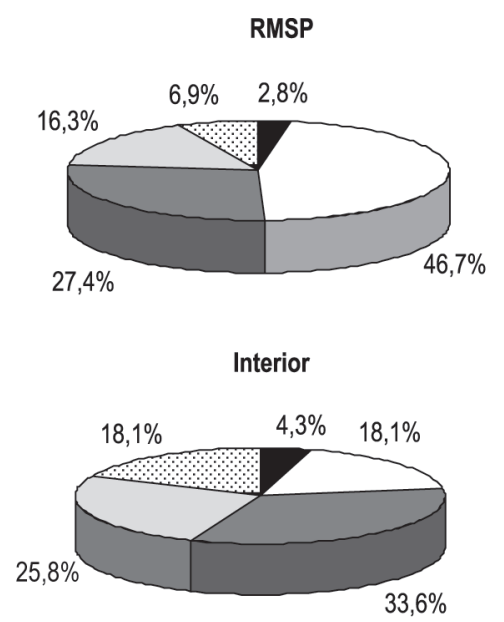

—Norte $\square$ Nordeste $\square$ Sudeste (1) $\square$ Sul $₫$ Centro-Oeste

Fonte: IBGE. Censo Demográfico do Estado de São Paulo de 2000. (1) Refere-se ao Estado de São Paulo, excluindo-se a RMSP. a outros estados brasileiros - correspondendo a $61,6 \%$ das pessoas que deixaram o Estado nesse período (CUNHA, 1987; PERILLO; PERDIGÃO, 2000). A grande área de absorção dos fluxos foi a Região Nordeste, responsável por $46,7 \%$ da emigração da RMSP nesse período. Em menor proporção, seguiram-se Sudeste $(27,4 \%)$ e Sul $(16,3 \%)$ (Gráfico 4). Destacaram-se os Estados da Bahia (15,3\%), Paraná $(11,5 \%)$ e Pernambuco $(8,4 \%)$.

Chama a atenção o papel relevante da capital, que é a maior porta de entrada e de saída da população paulista: cerca de 380 mil pessoas deixaram essa área entre 1995 e 2000. Os principais locais de destino dos migrantes foram os Estados de Minas Gerais (20,7\%), Bahia (16,2\%) e Paraná $(10,7 \%)$.

Praticamente 310 mil pessoas saíram do interior paulista em direção a outros estados. As áreas mais atrativas dessa população foram as Regiões Sudeste e Sul, sobretudo, os Estados de Minas Gerais $(27,2 \%)$ e Paraná (20,6\%) (Gráfico 4).

TABELA 4

Emigração, segundo Regiões Administrativas Estado de São Paulo - 1995-2000

\begin{tabular}{|c|c|c|c|}
\hline \multirow[b]{2}{*}{ Regiões Administrativas } & \multicolumn{3}{|c|}{ Emigração (Destino) } \\
\hline & $\begin{array}{c}\text { Total } \\
(1)\end{array}$ & Em São Paulo & $\begin{array}{c}\text { Fora de } \\
\text { São Paulo }\end{array}$ \\
\hline Estado de São Paulo & 1.909 .836 & 53,7 & 46,3 \\
\hline RMSP & 1.067 .998 & 47,4 & 52,6 \\
\hline Registro & 18.971 & 73,5 & 26,5 \\
\hline RM da Baixada Santista & 81.874 & 58,4 & 41,6 \\
\hline São José dos Campos & 67.753 & 45,1 & 54,9 \\
\hline Sorocaba & 85.628 & 63,6 & 36,4 \\
\hline Campinas & 191.909 & 53,0 & 47,0 \\
\hline Ribeirão Preto & 53.997 & 61,6 & 38,4 \\
\hline Bauru & 43.341 & 74,8 & 25,2 \\
\hline São José do Rio Preto & 54.781 & 70,5 & 29,5 \\
\hline Araçatuba & 44.381 & 69,9 & 30,1 \\
\hline Presidente Prudente & 54.921 & 64,9 & 35,1 \\
\hline Marília & 52.932 & 76,0 & 24,0 \\
\hline Central & 36.258 & 74,9 & 25,1 \\
\hline Barretos & 26.663 & 72,2 & 27,8 \\
\hline Franca & 28.429 & 48,2 & 51,8 \\
\hline
\end{tabular}


A saída de população de São Paulo para outros estados do país foi bastante pronunciada em regiões como RMSP, São José dos Campos e Franca: nessas áreas, a migração externa (fora do Estado de São Paulo) representou mais de $50 \%$ dos deslocamentos populacionais ocorridos no período. Em contrapartida, em regiões como Registro, Bauru, Marília e Central, a participação da migração externa foi bem inferior: da ordem de $25 \%$ do total dos deslocamentos populacionais (Tabela 4).

\section{CONTEXTO DOS DESLOCAMENTOS INTRA-ESTADUAIS}

As informações censitárias de 2000 revelam que, além dos movimentos migratórios interestaduais, outras formas de mobilidade adquiriram importância e significado analítico nas últimas décadas. No Estado de São Paulo, passaram a se destacar os movimentos intra-estaduais: entre 1995 e 2000, o volume de migrantes do Estado (excetuando-se os deslocamentos intra-regionais) foi de 2,3 milhões de pessoas. Desse total, $54,8 \%$ correspondiam a fluxos migratórios originários de outros estados brasileiros e $45,2 \%$ a movimentos ocorridos no próprio Estado de São Paulo.

Este continuou apresentando intensa mobilidade populacional: entre 1986 e 1991, 1,3 milhão de pessoas movimentaram-se entre as regiões; entre 1995 e 2000, esse número ficou em torno de 1 milhão - o que indica uma redução nos movimentos internos de aproximadamente $27 \%$.

A tendência migratória intra-estadual encontra-se associada ao fortalecimento do processo de interiorização do desenvolvimento econômico já iniciado em meados dos anos 70. Esse processo contribuiu, num primeiro momento, para uma desconcentração das atividades econômicas a partir da RMSP em direção ao interior do Estado. Como resultado, ocorreu um redirecionamento dos fluxos migratórios da metrópole para as regiões situadas nos eixos de maior desenvolvimento econômico do interior e maior retenção da população do interior em suas regiões de origem (CANO, 1988; ARAÚJO; PACHECO, 1996; PERILLO, 1996; ARANHA, 1996; FUNDAÇÃO SEADE, 2004). Nos anos 90, intensificou-se a tendência de interiorização econômica e populacional do Estado. Segundo Araújo (1999), esse processo ocorreu em um espaço concentrado num raio de aproximadamente $150 \mathrm{~km}$ a partir do centro da RMSP, abrangendo as RAs de Campinas, São José dos Campos, Sorocaba e RM da Baixada Santista. Nesse contexto, Caiado (1996) destaca que, além dos centros industriais já consolidados do
Estado, como as RAs de Campinas, São José dos Campos e a RM da Baixada Santista e seus respectivos entornos, foram privilegiados os grandes eixos de ligação com a capital paulista - notadamente as cidades com melhor infra-estrutura em seu entorno, cortadas pelas rodovias Bandeirantes, Anhangüera, Presidente Dutra, Carvalho Pinto, Castelo Branco, Marechal Rondon e Fernão Dias.

As mudanças que vêm ocorrendo na dinâmica econômica e populacional da metrópole tiveram impactos significativos no conjunto de regiões que integram o interior. Essa área tem-se caracterizada como a segunda concentração industrial do país, só perdendo para a RMSP, e tem apresentado uma intensa mobilidade populacional, consolidando-se como uma das principais áreas migratórias do país nas últimas décadas (CUNHA, 1987; PERILLO; ARANHA, 1998; UNICAMP/NEPO, 1997).

Esse cenário econômico contribuiu, em grande medida, para o redirecionamento dos fluxos migratórios para as regiões de maior dinamismo do Estado, principalmente para as duas áreas metropolitanas - São Paulo e Baixada Santista - e para as RAs de Campinas e Sorocaba, entre outras.

\section{Capital: Maior Porta de Saída dos Migrantes que Deixaram a RMSP}

Entre 1995 e 2000, 468 mil pessoas saíram da RMSP e foram para as regiões do interior do Estado. Relevante é o papel da capital que, mesmo consolidando-se como importante pólo de atração populacional, caracterizou-se como a maior área de saída da população da metrópole: 320 mil pessoas deslocaram-se dessa área - o equivalente a 68,5\% dos migrantes que deixaram a RMSP. Apenas 148 mil pessoas $(31,5 \%)$ mudaram de outros municípios da RMSP (excetuando-se São Paulo) para o interior do Estado. As regiões do interior que mais se beneficiaram com os deslocamentos originados na RMSP foram as RAs de Campinas, Sorocaba, São José dos Campos e a RM da Baixada Santista (RMBS).

Os deslocamentos populacionais procedentes do interior do Estado foram menos pronunciados: 172 mil pessoas saíram do interior em direção à RMSP; dentre estas, 91 mil $(52,8 \%)$ movimentaram-se para os outros municípios da RMSP e 81 mil $(47,2 \%)$ para o Município de São Paulo (Mapa 2). Destacaram-se os fluxos originários das RAs de Campinas, Sorocaba, São José dos Campos e da RM da Baixada Santista. 


\section{MAPA 2}

Fluxos Migratórios Intra-Estaduais

Estado de São Paulo - 1995-2000

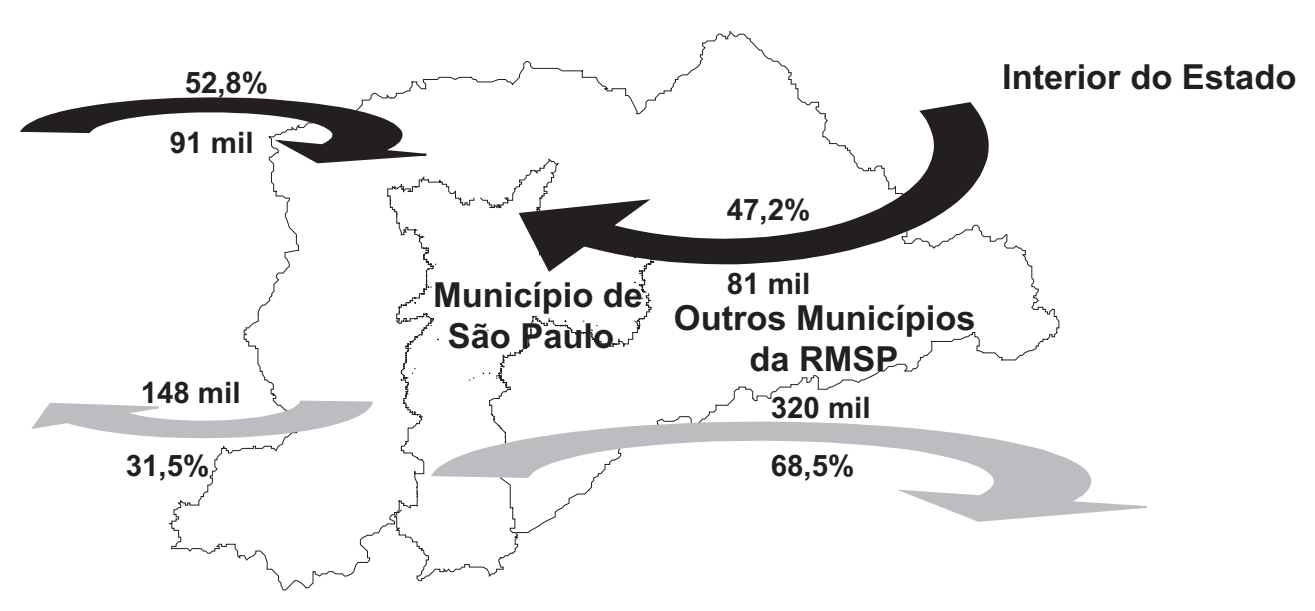

Fonte: IBGE; Fundação Seade.

Trocas Migratórias: 1 Milhão de Pessoas Deslocaramse entre as Regiões

Os deslocamentos populacionais no Estado de São Paulo foram pronunciados: praticamente 1 milhão de pessoas movimentaram-se entre suas regiões, no período 1995-2000.

Na RMSP, a participação dos deslocamentos intra-estaduais foi relativamente pequena, 19\% (Tabela 5). Essa região recebeu um volume de 172 mil pessoas e exibiu uma perda migratória acentuada, de 468 mil pessoas para as regiões do interior do Estado nesse período. Isso significa que, mesmo caracterizada como grande pólo de atração de migrantes, a RMSP consolidou-se como a principal área de saída da população. No balanço das trocas migratórias, essa área perdeu quase 300 mil pessoas para as outras regiões do interior. A região que mais se beneficiou com os deslocamentos da RMSP foi a de Campinas, que recebeu praticamente 144 mil migrantes dessa área. Dentre os migrantes que chegaram à metrópole, destacaram-se os procedentes de Campinas (16,9\%), RMBS (10,9\%), Sorocaba (10,1\%) e São José dos Campos (8,3\%).

A capital paulista foi o local preferido dos migrantes que saíram das regiões de Campinas e RMBS. Em contrapartida, os migrantes procedentes das regiões de Sorocaba e São José dos Campos concentraram-se, em sua maioria, nos outros municípios da RMSP (excetuando-se
São Paulo). Dentre as regiões que integram o interior, Campinas foi a que recebeu o maior volume de migrantes intra-estaduais entre 1995 e 2000: cerca de 235 mil pessoas mudaram para essa área. Sobressaíram-se os deslocamentos com origem na RMSP, responsáveis por $61,2 \%$ dos fluxos para a RA de Campinas. Praticamente 68\% dos migrantes que chegaram à região de Campinas saíram da capital e apenas $32 \%$ dos outros municípios da RMSP. Em menor expressão, Campinas recebeu migrantes das regiões de Sorocaba $(5,9 \%)$, Presidente Prudente $(3,7 \%)$ e São José do Rio Preto (3,6\%) (Mapa 3). A região de Campinas também se caracterizou como importante área de saída de migrantes para a RMSP $(31 \%)$, e para as regiões de Sorocaba $(13,7 \%)$ e São José do Rio Preto $(9,9 \%)$ (Tabela 6). No balanço das trocas migratórias, essa região exibiu um ganho líquido de 140 mil pessoas nesse período.

Outro importante pólo de atração populacional foi a região de Sorocaba, que recebeu 116 mil pessoas entre 1995-2000. Destacaram-se os deslocamentos com origem na RMSP (62,9\%), principalmente na capital $(63 \%) \mathrm{e}$, em menor expressão, os procedentes das RAs de Campinas, Marília e Bauru. O destino preferido das pessoas que saíram de Sorocaba foi a RMSP $(34,6 \%)$, seguida das regiões de Campinas $(27,3 \%)$ e Bauru (8,5\%). Entre 19952000, Sorocaba apresentou um ganho líquido de 66 mil pessoas nas trocas populacionais estabelecidas com as demais regiões do Estado. 


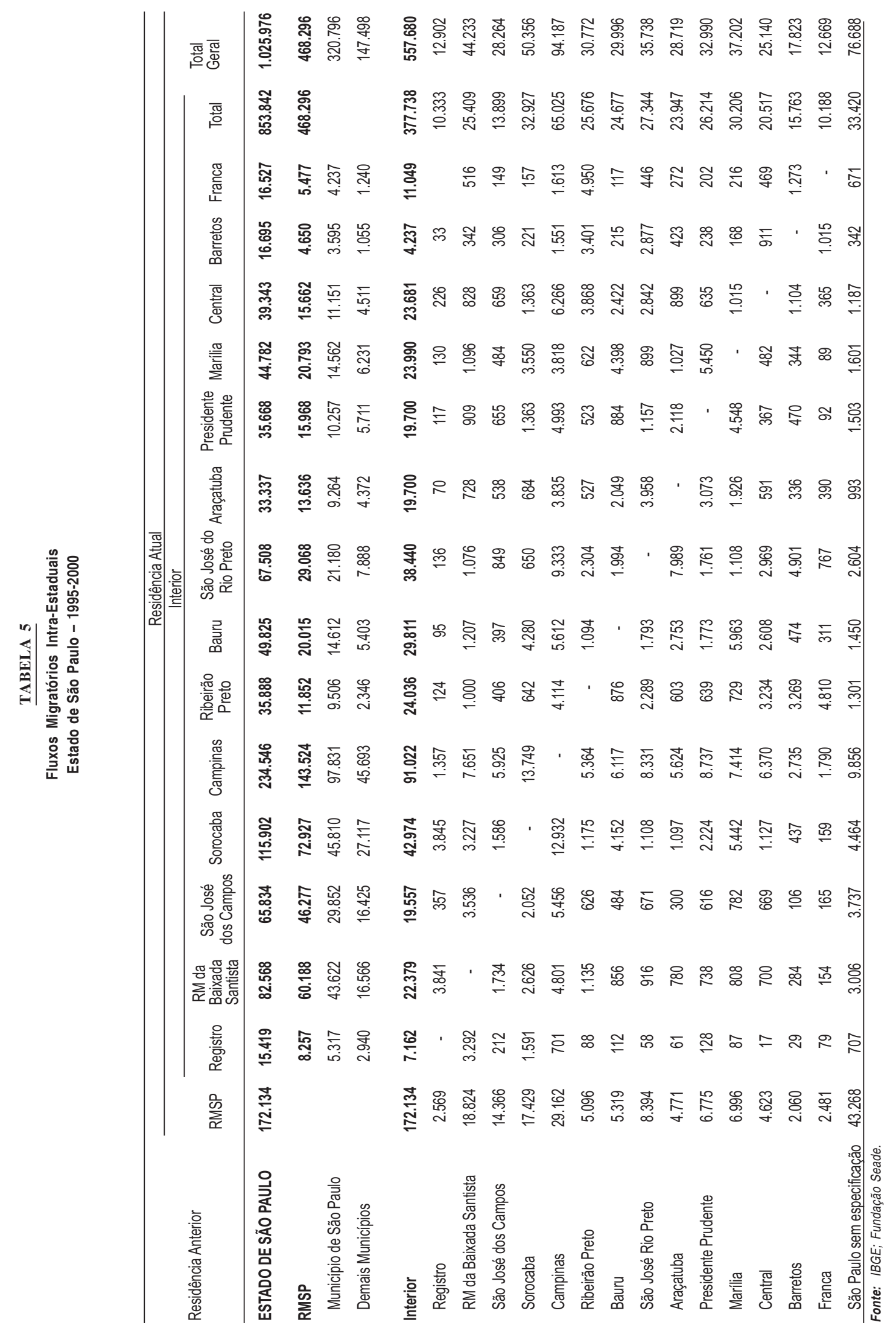


MAPA 3

Fluxos Migratórios Intra-Estaduais Numericamente mais Importantes Estado de São Paulo - 1995-2000

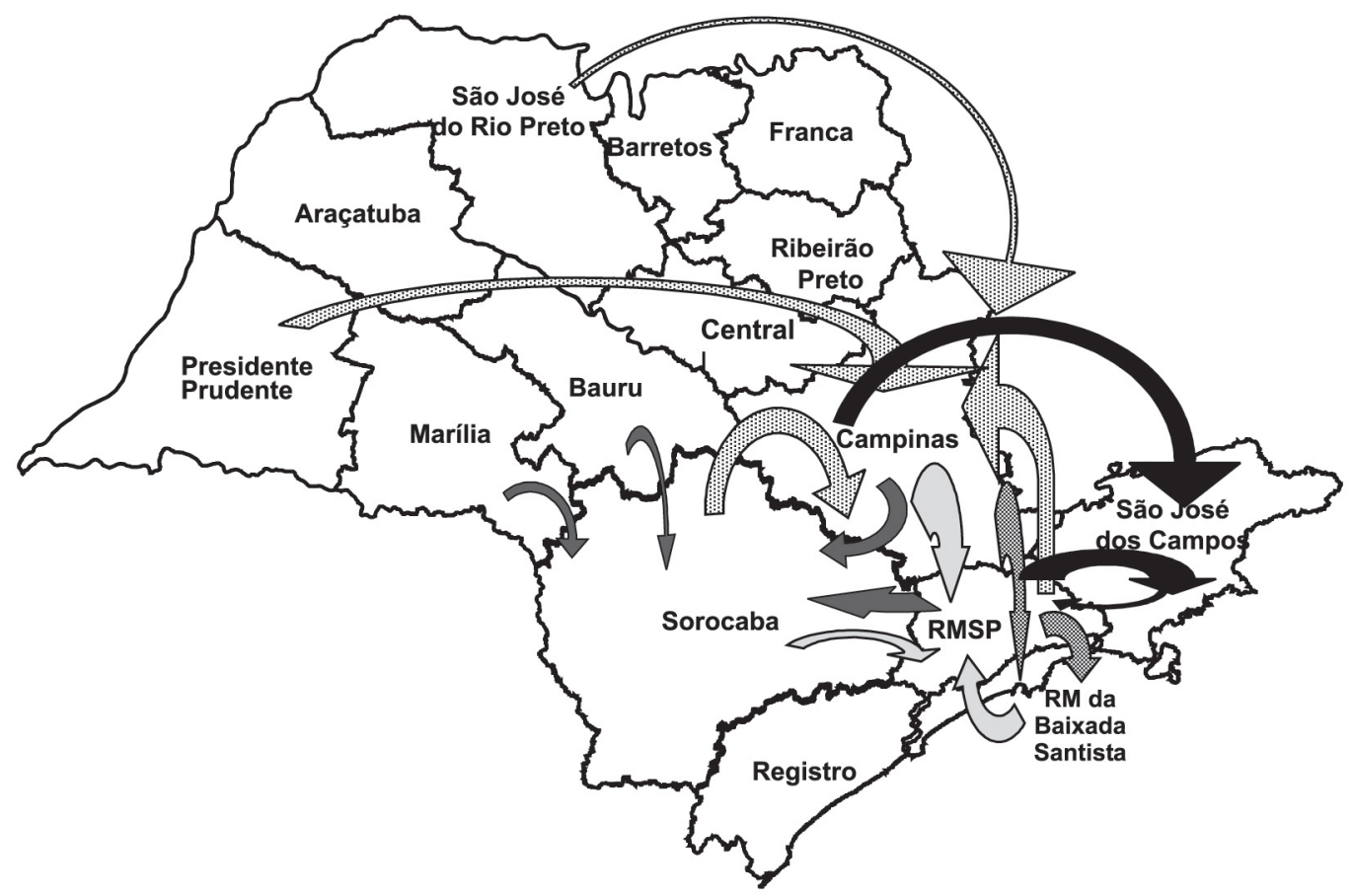

Fonte: IBGE; Fundação Seade.

TABELA 6

Fluxos Migratórios Intra-Estaduais Numericamente mais Significativos, segundo Áreas de Origem e Destino Estado de São Paulo - 1995-2000

\begin{tabular}{|c|c|c|c|c|c|c|}
\hline Áreas & Imigrantes & Emigrantes & Origem dos Imigrantes & $\%$ & Destino dos Emigrantes & $\%$ \\
\hline \multirow[t]{3}{*}{ RMSP } & 172.134 & 468.296 & Campinas & 16,9 & Campinas & 30,6 \\
\hline & & & RM da Baixada Santista & 10,9 & Sorocaba & 15,6 \\
\hline & & & Sorocaba & 10,1 & RM da Baixada Santista & 12,9 \\
\hline \multirow[t]{2}{*}{ RM da Baixada Santista } & 82.568 & 44.233 & RMSP & 72,9 & RMSP & 42,6 \\
\hline & & & & & Campinas & 17,3 \\
\hline \multirow[t]{2}{*}{ São José dos Campos } & 65.834 & 28.264 & RMSP & 70,3 & RMSP & 50,8 \\
\hline & & & Campinas & 8,3 & Campinas & 21,0 \\
\hline \multirow[t]{2}{*}{ Sorocaba } & 115.902 & 50.356 & RMSP & 62,9 & RMSP & 34,6 \\
\hline & & & Campinas & 11,2 & Campinas & 27,3 \\
\hline \multirow[t]{2}{*}{ Campinas } & 234.546 & 94.187 & RMSP & 61,2 & RMSP & 31,0 \\
\hline & & & Sorocaba & 5,9 & Sorocaba & 13,7 \\
\hline \multirow[t]{3}{*}{ São José do Rio Preto } & 67.508 & 35.738 & RMSP & 43,1 & RMSP & 23,5 \\
\hline & & & Campinas & 13,8 & Campinas & 23,3 \\
\hline & & & Araçatuba & 11,8 & Araçatuba & 11,1 \\
\hline
\end{tabular}

Fonte: IBGE; Fundação Seade. 
A RMBS recebeu 83 mil migrantes nesse período; a grande parcela dos fluxos $(73 \%)$ teve origem na RMSP, notadamente na capital. Em menor expressão, destacaramse os movimentos originários das RAs de Campinas, Registro e Sorocaba. Os migrantes que saíram da RM da Baixada Santista tiveram como principais áreas de destino a RMSP $(42,6 \%)$ e a RA de Campinas $(17,3 \%)$. Nas trocas populacionais efetuadas com as demais regiões do Estado, a RM da Baixada Santista registrou um ganho líquido de 38 mil pessoas.

Outro importante pólo de atração foi a Região de São José do Rio Preto, que recebeu quase 68 mil migrantes nesse período. Destacaram-se os fluxos procedentes da RMSP $(43,1 \%)$ e, em menor proporção, das RAs de Campinas e Araçatuba. Nesse período, a Região de São José do Rio Preto apresentou perdas populacionais importantes para a RMSP $(23,5 \%)$ e para a RA de Campinas $(23,3 \%)$.

A RA de São José dos Campos recebeu 65 mil pessoas procedentes, em sua maioria, da RMSP (70\%). Os migrantes que saíram da Região de São José dos Campos tiveram como principais áreas de destino a RMSP (51\%) e a RA de Campinas (21\%). Dentre as regiões caracterizadas como pólo de atração do Estado de São Paulo, a Região de São José dos Campos foi a que exibiu as menores perdas populacionais nas trocas estabelecidas no período 1995-2000, da ordem de 28 mil pessoas (Tabela 6).

As regiões analisadas foram as que apresentaram os fluxos migratórios intra-estaduais numericamente mais significativos, consolidando-se como as áreas de grande atração da população que se deslocou dentro do Estado de São Paulo. Entre 1995 e 2000, essas áreas responderam em conjunto por praticamente $72 \%$ da migração intra-estadual.

\section{CONSIDERAÇÕES FINAIS}

Os resultados apresentados mostram a importância das migrações interestaduais e apontam que o Estado de São Paulo continuou sendo o principal pólo nacional de atração migratória entre 1995 e 2000. A migração desempenhou papel relevante na RMSP - principalmente na capital, que ainda exerce forte atração no redirecionamento da população vinda de Estados brasileiros para São Paulo. Bahia, Minas Gerais, Paraná e Pernambuco consolidaram-se como as principais áreas de procedência dos migrantes que chegaram a São Paulo. As principais áreas de destino dos migrantes que saíram do Estado de São Paulo foram Minas Gerais, Paraná, Bahia e Pernambuco.
As informações censitárias de 2000 revelam que, além dos movimentos migratórios interestaduais, outras formas de mobilidade vêm adquirindo importância e significado analítico nas últimas décadas. Além dos movimentos interestaduais, os intra-estaduais passaram a ter um papel cada vez maior, respondendo por 45,2\% dos fluxos migratórios para o Estado de São Paulo entre 1995 e 2000. Praticamente um milhão de pessoas deslocaram-se entre as regiões do Estado nesse período. Os principais fluxos migratórios ocorreram para as regiões de maior dinamismo econômico, sobressaindo-se as áreas metropolitanas de São Paulo e da Baixada Santista e as RAs de Campinas, Sorocaba, São José dos Campos, entre outras.

Nos anos 90, o interior do Estado de São Paulo reforçou seu potencial de atração migratória, notadamente da população originária da RMSP. Por outro lado, mesmo caracterizada como o grande pólo de migrantes, a metrópole paulista, notadamente a capital, consolidou-se como a principal área de saída da população do Estado de São Paulo. No balanço das trocas migratórias intra-estaduais, essa região perdeu quase 300 mil pessoas para as outras regiões paulistas entre 1995 e 2000.

Ressalte-se, porém, que a maior parte das transformações econômicas e demográficas recentes que a RMSP vem apresentando concentram-se, sobretudo, na capital. Essa área continua centralizando grande parte das atividades mais dinâmicas e modernas do país, intensificando ainda mais sua característica de cidade "global" ou "mundial".

\section{NOTA}

1. Interior aqui definido como o conjunto de todas as regiões paulistas, excluindo-se a Região Metropolitana de São Paulo.

\section{REFERÊNCIAS BIBLIOGRÁFICAS}

ARANHA, V. Migração na metrópole paulista. São Paulo em Perspectiva, São Paulo, Fundação Seade, v. 10, n. 2, abr./jun. 1996.

ARAÚJO , M.F.I.; PACHECO, C.A. A trajetória econômica e demográfica na metrópole na década 70-80. In: SÃO PAULO (Estado). Cenários da urbanização paulista: documento básico. São Paulo: SEP/Fundação Seade, 1996. v. 6. (Coleção São Paulo no limiar do século XXI).

ARAÚJO, M.F.I. Mapa da estrutura industrial e comercial do Estado de São Paulo. São Paulo em Perspectiva, São Paulo, Fundação Seade, v. 13, n. 1-2, jan./jun. 1999. 
BAENINGER, R. Interiorização da migração em São Paulo: novas territorialidades e novos desafios. In: ENCONTRO NACIONAL DE ESTUDOS POPULACIONAIS, 14., 2004, Caxambu. Anais... Caxambu: Abep, 2004.

Expansão, redefinição ou consolidação dos espaços de migração em São Paulo? Análises a partir dos primeiros resultados do Censo 2000. In: ENCONTRO NACIONAL DE ESTUDOS POPULACIONAIS, 13., 2002, Ouro Preto. Anais... Ouro Preto: Abep, 2002.

BRANCO, P.P.M. Informação e missão institucional: pesquisa desvenda economia paulista. São Paulo em Perspectiva, São Paulo, Fundação Seade, v. 13, n. 1-2, jan./jun. 1999.

CAIADO, A.S.C. Desconcentração industrial regional no Brasil: pausa ou retrocesso 1985-1998. Tese (Doutorado) - Instituto de Economia da Universidade Estadual de Campinas, Campinas, 2002

Desenvolvimento regional: novos requisitos para a localização industrial em São Paulo. São Paulo em Perspectiva, São Paulo, Fundação Seade, v. 10, n. 2, abr./jun. 1996.

CANO, W. et al. A nova realidade da indústria paulista: subsídios para a política de desenvolvimento regional do Estado de São Paulo. Campinas: IE/Unicamp/Fecamp, 1994. (Relatório de Pesquisa).

CANO, W. Notas para um cenário migratório no Estado de São Paulo. São Paulo em Perspectiva, São Paulo, Fundação Seade, v. 10 , n. 2, abr./jun. 1996.

CANO, W. (Coord.). A interiorização do desenvolvimento econômico do Estado de São Paulo (1920-1980). São Paulo: Fundação Seade, 1988. (Coleção Economia Paulista, v. 1, n. 3).

CUNHA, J.M.P. da. Mobilidade populacional e expansão urbana: o caso da Região Metropolitana de São Paulo. Tese (Doutorado) IFCH/Unicamp, Campinas, 1994.

A migração nas regiões administrativas de São Paulo segundo o Censo de 80. Revista Brasileira de Estudos de Popula ção, São Paulo, v. 4, jul./dez. 1987.

As correntes migratórias na Grande São Paulo. São Paulo em Perspectiva, São Paulo, Fundação Seade, v. 1, n. 2, jul./set. 1987

CUNHA, J.M.P. da.; DEDECCA, C.S. Migração e trabalho na Região Metropolitana de São Paulo nos anos 90: uma abordagem sem preconceito. Revista Brasileira de Estudos de População, Abep, v. 17, n. 1-2, jan./dez. 2000

FUNDAÇÃO SEADE. Projeções para o Estado de São Paulo: população e domicílios até 2025. São Paulo, Fundação Seade/ Sabesp, ago. 2004.

MADEIRA, F.R.; TORRES, H.G. População e reestruturação produtiva. Novos elementos para projeções demográficas. São Paulo em Perspectiva, São Paulo, Fundação Seade, v. 10, n. 2, abr./jun. 1996.

NEGRI, B.; PACHECO, C.A. Mudança tecnológica e desenvolvimento regional nos anos 90: da interiorização do

desenvolvimento à nova dimensão espacial da indústria paulista. In: SUZIGAN, W.; COUTINHO, L. (Coord.). Projeto

desenvolvimento tecnológico e competitividade da indústria brasileira. Campinas: SCTDE/Fecamp/Unicamp-IE, 1993.
OLIVEIRA, A.T. de.; SIMÕES, A. G. Deslocamentos populacionais no Brasil: uma análise dos censos demográficos de 1991 e 2000. In: ENCONTRO NACIONAL DE ESTUDOS POPULACIONAIS, 14., 2004, Caxambu. Anais... Caxambu: Abep, 2004.

PATARRA, N.; BAENINGER, R. Movimentos migratórios: novas características, novas indagações. In: ENCONTRO DA ASSOCIAÇÃO NACIONAL DE PLANEJAMENTO URBANO E REGIONAL - ANPUR, 3., Águas de São Pedro, Ipea/Nesur/ IBGE, 2000.

Regionalização em São Paulo: novas tendências ou consolidação de processos recorrentes? Campinas: Nesur/IE/

Unicamp, Convênio Fundação Seade-Fecamp, 1994. (Relatório de pesquisa do projeto: A nova realidade socioeconômica do Estado de São Paulo).

PERILLO, S.R. Vinte anos de migração no Estado de São Paulo: uma análise do período 1980/2000. In: ENCONTRO NACIONAL DE ESTUDOS POPULACIONAIS, 13., 2002, Ouro Preto. Anais... Ouro Preto: Abep, 2002.

Novos caminhos da migração no Estado de São Paulo. São Paulo em Perspectiva, São Paulo, Fundação Seade, v. 10, n. 2, abr./jun. 1996.

PERILLO, S.R. Migração e mudanças: uma análise das tendências migratórias na RMSP no período 1980-1991. Conjuntura Demográfica, São Paulo, Fundação Seade, n. 22, 1993.

PERILLO, S.R.; ARANHA, V. Caminhos da migração: nova dinâmica demográfica. In: FUNDAÇÃO SEADE. Vinte anos no ano 2000: estudos sociodemográficos sobre a juventude paulista. São Paulo: 1998.

Novos padrões de reorganização espacial da população paulista. Conjuntura Demográfica, São Paulo, Fundação Seade, n. 26, jan./mar. 1994 .

PERILLO, S.R.; PERDIGÃO, M. O Estado de São Paulo continua sendo o principal pólo de migrantes do país. SP Demográfico, São Paulo, Fundação Seade, ano 4 , n. 6, set. 2003.

Cenários migratórios recentes em São Paulo. In: ENCONTRO NACIONAL DE ESTUDOS POPULACIONAIS, 12. 2000, Caxambu. Anais... Caxambu: Abep, 2000.

RODRIGUES, R. do N.; PERILLO, S.R. Perspectiva da migração no Estado de São Paulo e suas 11 Regiões Administrativas para o período 1980-2000. Informe Demográfico, São Paulo, Fundação Seade, n. 19, 1986.

UNICAMP/NEPO. Desenvolvimento econômico e crescimento populacional: tendências recentes e cenários futuros. Campinas, abr. 1997.

Sonia Regina Perillo: Estatística e Demógrafa, Analista da Fundação Seade (sperillo@seade.gov.br).

Magaly De Losso Perdigão: Tecnóloga em Processamento de Dados, Analistada Fundação Seade (mdelosso@seade.gov.br).

Artigo recebido em 23 de março de 2005.

Aprovado em 30 de maio de 2005. 